\title{
The Expression Method Exploration of Folk Culture in Urban Public Art --Take Paper-Cut Sculpture in Harbin Daowai's Northeast Folk Culture Series as Example
}

\author{
Zhenkun Han and Zhengzheng Tang
}

School of Architecture, Harbin Institute of Technology, 150001, No. 66, Xidazhi Street, Harbin City, Heilongjiang Province, China

1215158588@qq.com,26324049@qq.com

Keywords: Folk culture ;Expression method ;Northeast paper-cut ;Eighteen oddities in Northeast China; Thirty-six industries in Northeast China

\begin{abstract}
As the concept which reflects the most general rules of the popular culture, the folk culture is provided with the features of groupment, practicability, regionalism, stability as well as changeability. Northeasterners are admirably impressed by the unique folk culture which is created by the distinctive geographical conditions and history factors in northeast China. The folk culture expression by the urban public art will not only realize the innovation on the pattern, but also satisfy the inheriting of urban culture. The text takes the paper-cut sculpture in Harbin off-piste folk culture series as example to seek for the folk culture expression method in the urban public art.
\end{abstract}

\section{Folk Culture Overview}

The Concept of Folk Culture. Folk, namely, the folk customs. Refers to the general term of the folk living culture of the folk people. It also refers to the folk living customs which are created, shared and inherited by the public of a country, people and region in general. It is a series of substantial and spiritual cultural phenomenon which is formed by the common mass in the production and live process.

The expression methods of folk culture are diversified, such as languages, characters and other symbols; In addition, it may be expressed in abstract personality, value views, etc. Or, material carrier, such as, the folk culture in northeast China is considered as one characteristic branch of Chinese folk cultures.

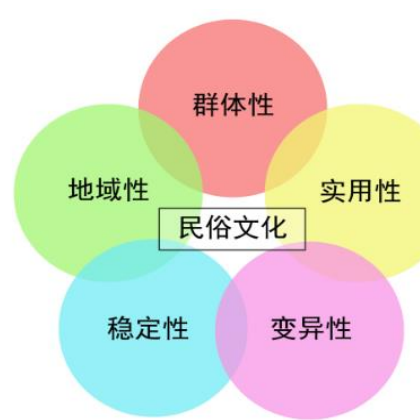

Figure 1. The schematic diagram for folk culture property

Folk Culture Property . Groupment . The groupment is the primary feature in the folk culture. Firstly, the folk culture is formed step by step, which can be reserved and inherited only being recognized and approved by the mass in the formation process. Secondly, the folk culture is the achievement of mass intelligence creation and the crystallization of many persons even several generations after layers of filtering. Thirdly, the folk culture is followed by the mass.

Practicability . Practicability is deemed as the most essential feature of folk culture. The folk culture is at the service of people's production and life, in the meantime, people will seek for the spiritual enjoyment from the folk culture. Many folk cultures play an effective role in the real life of the mass. Such as, the northeast Younger and other folk activities have developed into the favorite recreational projects by the mass in Northeast China. 
Localization. The folk culture formation is closely related to the living natural environment of the people. The different living environments result in the differentiation in people's necessities, in such case, the folk culture in different regions is equipped with the different individualities to bring about diversified production modes.

Stability and Variability. The folk culture has the relatively stable features due to the inheritance after people pass it on from generation to generation within the regional ranges. However, as the basic culture, the folk culture is not invariable in the inheritance and transmission process. Along with the continuous changes of the time and space, the folk culture is in the process of variation to gradually adapt to the footsteps of the time. The variability of the folk culture is mainly reflected in three kinds of changing modes, namely, expression pattern, folk culture property and the extinction of the old customs.

\section{The Significance of Urban Public Art of Expressing the Folk Culture}

As the thought of the city is the symbol of a city culture mature development, and the public art has reflected the urban identifying characteristics and cultural value views. The urban public art works which take folk culture as the title can vividly express the regional culture in the diversified way for the sake of carrying forward the national characteristics and enhancing the acceptance and belonging senses of the citizens for the located cities. The folk culture is capable of comprehensively reflecting the mass culture development conditions within the regions as a result of its evolution along with the history for the long term. The urban public art makes use of the new patterns and new methods to manifest the folk culture, structure the harmonious and amiable urban public space environment, as well as effectively maintain the diversity of urban culture. With the sufficient features, the folk culture has developed into the carrier for mass spirit, ethnical tradition and cohesion. In addition, the artistic expression means of the urban public art will be beneficial to create the culture image and manifest the distinctive culture individuality of the city.

\section{Folk Culture in Northeast China}

The Formation and Development of Folk Culture in Northeast China. The northeast folk culture is composed by the national customs of four phyletic lines in northeast China. Firstly, the Manchu customs. Based on the fishing and hunting life, the traditional customs of Manchu have great influences on the current days. Painting, paper-cut, singing and dancing, as well as folk art forms have survived from the original Manchu nationality; Secondly, the Han nationality customs, including the original Han and the subsequent Han nationality in northeast China, which is based on farming life; Thirdly, the Mongol nationality customs, based on nomadic life; Finally, Huimo nationality, still plays an influence on the folk culture in Northeast China regardless of its extinction. The folk customs of various nationalities are mutually integrated along with the time variation as well as continuous developments and changes of many factors to form the unique folk culture in northeast China.

Features and National Personality of Northeast Folk Culture . The national personality refers to the attitude of a nationality for heaven, earth and people, and the corresponding behavior features. The northeasters develop the northeast folk culture, in turn, the northeast folk culture puts some influences on the northeasters' character development. The northeast folk culture is based on the customs' integration between minorities and Han nationality, which can not only reflect the pioneering spirits of daring to struggle and forging ahead with determination, but also manifest the down-to-earth feature and seeking for reality in stability ${ }^{[1]}$. The northeasters are content with the current status due to the easy survival and living as a result of the nature and climate conditions in northeast China. 


\section{The Expression of Northeast Folk Culture in Urban Public Art--Take Paper-Cut Sculpture in Harbin Off-Piste Folk Culture Series as an Example}

Basic Conditions. The wave wall with more than kilometers, which lies on the Songhua River, Daowai District of Harbin City will be used to create the northeast folk customs' series paper-cut sculpture corridor at present. Taking the northeast paper-cut for window decoration as the template, the sculpture will vividly reproduce the paper-cut for window decoration situations in northeast China. There are more than fifty scenes in the whole sculpture. The specific contents take the "eighteen oddities" and "thirty-six industries" in northeast China as the subject (Fig. 2).

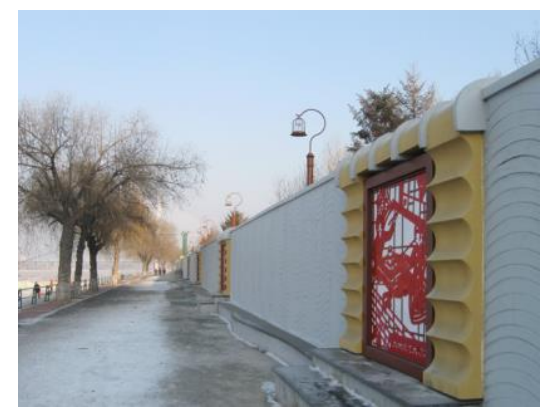

Figure 2 Sculpture corridors

Public Art Pattern Selection. As for the sculpture pattern selection, the paper-cut is chosen after taking the wave wall observation, construction cost and ecology into account. Paper-cut is the most ancient and characteristic pattern in Chinese folk arts, what's more, it is extremely popular in northeast China. With the uninterrupted structures after numerous shearing, the paper-cut lines are requested to be smooth with certain artistic effect; In general, the bright color shall prevail for the paper-cut. With the dense happy and propitious colors as well as vivid and abstract expression pattern, the paper-cut has developed into the idealized creation pattern.

Folk Culture Expression in Northeast China. Eighteen Oddities in Northeast China. The northeasters in northeast China have formed the unique living habits as well as local conditions and customs due to the special climate and ecological environment. Along with the enthusiasm for "Chuang Guandong", people inside Shanhaiguan firstly caught sight of the different customs and habits after coming to northeast China, hence, they summarized some doggerels, such as "three oddities", "four oddities" and "eight oddities" in northeast China for the sake of describing their observed northeast China, up to now, the northeast "eighteen oddities" have gradually been concluded. These "eighteen oddities" doesn't necessarily represent the whole northeast customs. In addition, there will be different statements due to different inductions.

Specially, the northeast "eighteen oddities" include "dog doesn't bark youngster in case of jumping off the wall, infants are placed within the hoisting basket, chimney is installed outside the mountain wall, daughter-in law wears shoes of father-in-law wrong, the tracing pole stamps on the outdoor, girl loves Shagai, the fur-lined jacket is reversed dressed with the outward fur, make steamed bun stuffed with sweetened bean in winter and tell ghost stories, the unmarried young girls climb trees quicker than monkeys, horse-pulling sledge is quicker than car pulling, eat Chinese sauerkraut instead of fresh vegetables, grass-mat house is mounted with fence, window paper is pasted outside, unmarried young girls smoke tobacco pipes, the steamed bun stuffed with sweetened bean paste is popular during festival celebrations, stew vegetables below with pancake cooking above, dance shaman to drive disease and demon, as well as place four dishes on the desk in the first place". The foregoing oddities express the northeast customs from the life necessities, entertainment and recreation to develop into the matters with the most northeast features.

"Window paper is pasted outside" refers to a kind of warm protection measure of northeasters. Due to the chilling winter in northeast China, the northeast people always paste the window papers on the outside of the small-grid windows to avoid moistening of window papers by the vapor (deriving from the indoor and outdoor temperature difference), in summary, it has fully reflected the regional features and practicability of northeast customs. However, we can't see the custom at 
present. Hence, the paper-cut sculpture will imitate the past northeast customs to reproduce the scene of "Window paper is pasted outside" as the original shapes (Fig. 3)

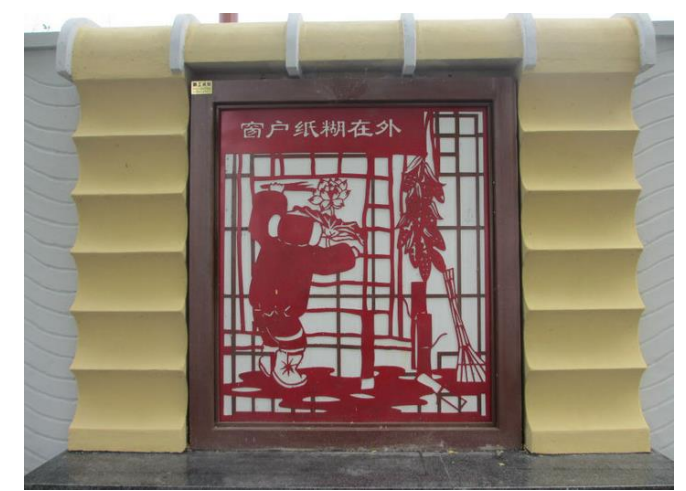

Figure 3 Window paper is pasted outside basket

"Infants are placed within the hoisting basket" refers to a kind of baby-sit method of northeasters. In the two phyletic lines in northeast customs (Manchu and Mongol nationality), the females shall also ride on horses as the nationality on horseback, as a result, they were unable to take their infants along. In order to prevent the injury from wild animals, they weaved the rocky trolley by the birch bark to place the children and hang it in the tree. In later times, the foregoing custom is still kept and improved regardless of the enhanced living conditions. The north Hans also applied the foregoing method for fostering infants, however, they just hang the rocky trolley on the beam. The young mother on the paper-cut sculpture pushes the rocky trolley in good-tempered with the around manual labors. She will continue to begin to work as long as her infant calms down (Fig. 4).



Figure 4 Infants are placed within the hoisting

"Unmarried young girls smoke tobacco pipes" describes the behavior of the unmarried young girls to smoke the tobacco pipes in northeast China. It looks like very vulgar without womanliness. The reason is that females are also requested to participate in the heavy manual works in northeast China, hence, they also need to recover from fatigue by smoking just like man after working from dawn to night. In the paper-cut work, two northeast girls sit at white-picket fence to smoke the tobacco pipes, thereinto, one girl raises the pipe up to jauntily speak something. In the past times, if one girl was seen to smoke the tobacco pipe in northeast China, it was stated that she was a hard-working person from her childhood. Hence, we can see that the foregoing behavior is considered as the symbol for unyielding and magnanimous characters of northeast female, and one feature of the northeast nationality (Fig. 5). 


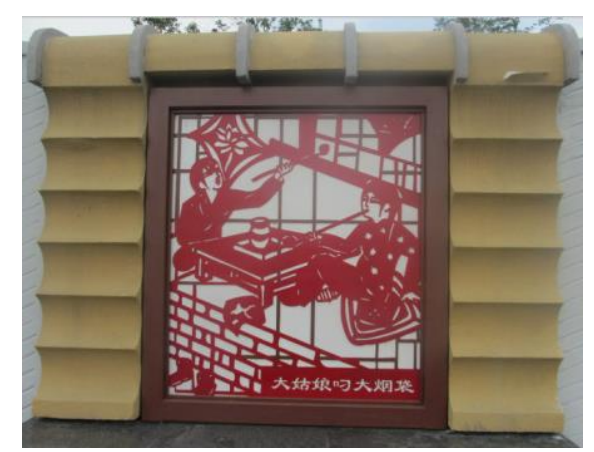

Figure 5. Unmarried young girls smoke tobacco pipes.

Thirty-six Industries in Northeast China. In Qingbaileichao ·Agri-businesses class: "The thirty-six industries, refer to various kinds of professions. We call it thirty-six industries by the labor division. If we double it, we can call seventy-two industries. In case of tenfold amount, it will be three hundred and sixty industries." At present, the common-said seventy-two or three hundred and sixty industries do not refer to the specific figures. Due to the difference in regions, the definite of thirty-six industries is slightly different. In northeast China, there is also folk thirty-six industries, such as, sell peddler, storyteller, persons of syrup stirring, raw cylinder artisan, lantern maker, blacksmith, etc.

The "sell peddler" refers to the name of persons who sell the general merchandises in northeast China by wandering about the street, which was still popular in rural areas until the last 70s or 80s century. The sell peddlers will generally carry large bamboo baskets or push the trolleys to every place, or shake the rattle. When the vendor's cyies of the sell peddlers rise, children will feel happy. One northeast folk song New Sell Peddler vividly describes the occupation, "hey...... Play drums and beat the gong to push the trolley to deliver goods. The cargos on the trolley are really good and nice......" In the paper-cut sculpture, the gracious smile and diligent attitude of the peddlers are the portrayal of the northeast merchant characteristics (Fig. 6).

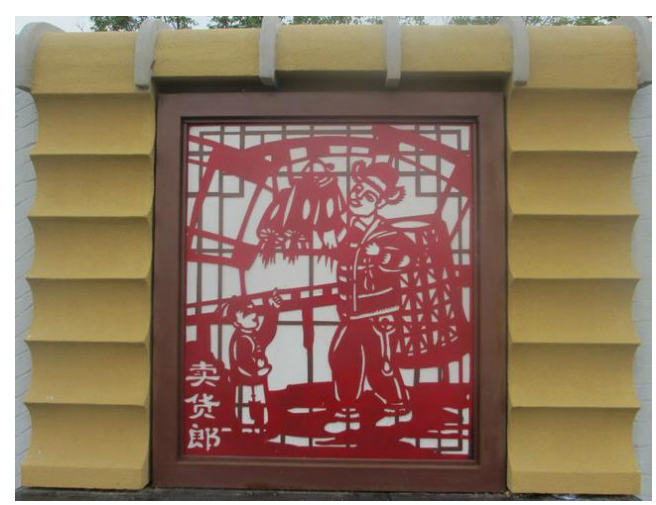

Figure 6 Sell peddler

The "person of syrup stirring" is also one pleased and delighted industry in the northeast regions in those years. The northeast China is suitable for planting beets due to the chilled climate. In the past, females always cut the beet fruits into thin strips and boiled them with water in the cauldron as a result of the less non-staple foods in the northeast China, until the beet water was boiled into viscous starch in amber color, afterwards, the syrup was generated. With the thick, sweet taste, the syrup can be stored for usage in the future after the solidification. In the paper-cut sculpture, a northeast girl is described to stir the syrup (Fig. 7). 


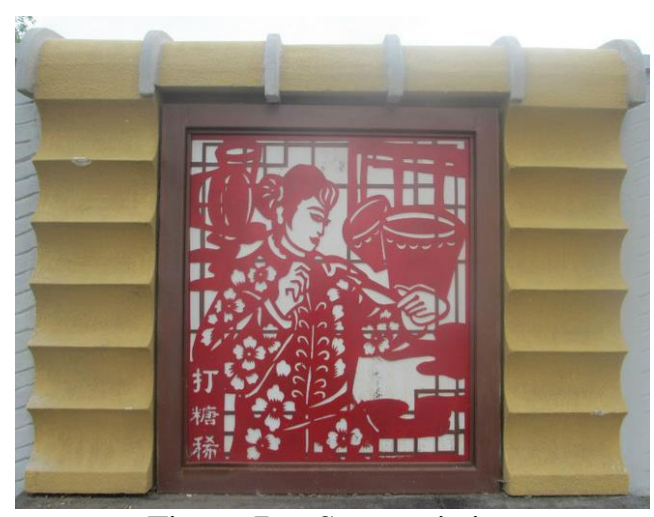

Figure 7. Syrup stirring

The "lantern making" is one New Year customs in northeast regions. People always hang the lanterns which stand for family reunion signing up to create a festive atmosphere before and after the Festival of Lanterns (the 15th day of lunar January of every year). After the inheri, the abundant and colorful categories and mastered technique levels have been formed. In this paper-cut sculpture, two tance and development of generations of illuminating artistslantern makers hold a palace lantern to be world-renowned by right of the elegance and palace style (Fig. 8).

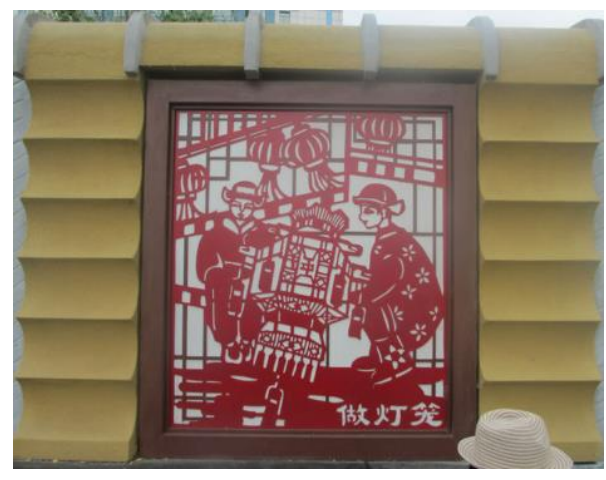

Figure 8. Lantern making

\section{Summary}

The unique geographic position and history culture of northeast China contributes to the featured northeast folk culture with the groupment, practicability, regionalism, stability as well as changeability to reflect the characteristics and national personality of the northeast folk culture. Many folk cultures have disappeared along with the times' development and society changes. When the urban public art reproduces the northeast folk culture by right of the artistic expression, people will recall the past times and enhance the belonging and intimacy senses for the located city to inherit the urban folk cultures in the innovative way.

\section{Reference}

[1] Luan Fan.The Outstanding Folk Culture Discussion in Northeast China [G], Social Science Front, 2009, 5

[2] Lv Haijing, Han Zhenkun. kirgiz plaza sculpture creation practice reflection[J],industrial design, 2014,11

[3] Han Zhenkun. Lv Haijing, study of Chinese national art[M] ,Beijing: China water conservancy and hydropower press, 2014 
[4] MiaoYanRong. China national art design[M] ,Shenyang: liaoning science and technology press, 2010

[5] Lv Haijing, Han Zhenkun.language of Chinese landscape painting aesthetics connotation analysis[J], grain in ear, 2014,11

[6] Zhao Meng. Sculpture art of China[M] , Beijing: people's fine arts publishing house, 2013

[7] Han Zhenkun. Kirgiz theme sculpture creation analysis method of study[J], journal of northeast agricultural university, 2011,2

[8] Zhang Qizhi. Chinese traditional culture[M], Beijing: higher education press, 2010

[9] Cheng Yuzhen.Chinese culture[M], Beijing: foreign language teaching and research press, 2011

[10]Huang Yanfang. Appreciate Chinese culture[M] , Beijing: China commercial press, 2011 